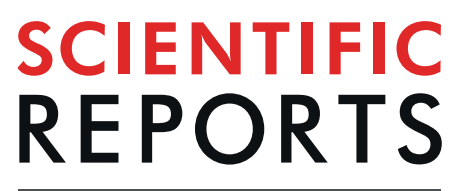

natureresearch

\title{
Genomic, metabolic and phenotypic variability shapes ecological differentiation and intraspecies interactions of Alteromonas macleodii
}

\begin{abstract}
Hanna Koch ${ }^{1,8,14}$, Nora Germscheid ${ }^{1,14}$, Heike M. Freese ${ }^{2}$, Beatriz Noriega-Ortega 3,9 , Dominik Lücking ${ }^{1}$, Martine Berger ${ }^{1}$, Galaxy Oiu ${ }^{4,10}$, Ezequiel M. Marzinelli $\mathbb{I}^{4,5,6,11}$, Alexandra H. Campbell ${ }^{4,12}$, Peter D. Steinberg ${ }^{4,5,6}$, Jörg Overmann ${ }^{2,7}$, Thorsten Dittmar ${ }^{3}$, Meinhard Simon $\mathbb{1}^{1}$ \& Matthias Wietz ${ }^{1,13^{*}}$

Ecological differentiation between strains of bacterial species is shaped by genomic and metabolic variability. However, connecting genotypes to ecological niches remains a major challenge. Here, we linked bacterial geno- and phenotypes by contextualizing pangenomic, exometabolomic and physiological evidence in twelve strains of the marine bacterium Alteromonas macleodii, illuminating adaptive strategies of carbon metabolism, microbial interactions, cellular communication and iron acquisition. In A. macleodii strain MIT1002, secretion of amino acids and the unique capacity for phenol degradation may promote associations with Prochlorococcus cyanobacteria. Strain 83-1 and three novel Pacific isolates, featuring clonal genomes despite originating from distant locations, have profound abilities for algal polysaccharide utilization but without detrimental implications for Ecklonia macroalgae. Degradation of toluene and xylene, mediated via a plasmid syntenic to terrestrial Pseudomonas, was unique to strain EZ55. Benzoate degradation by strain EC673 related to a chromosomal gene cluster shared with the plasmid of $A$. mediterranea $\mathrm{EC615}$, underlining that mobile genetic elements drive adaptations. Furthermore, we revealed strain-specific production of siderophores and homoserine lactones, with implications for nutrient acquisition and cellular communication. Phenotypic variability corresponded to different competitiveness in co-culture and geographic distribution, indicating linkages between intraspecific diversity, microbial interactions and biogeography. The finding of "ecological microdiversity" helps understanding the widespread occurrence of $A$. macleodii and contributes to the interpretation of bacterial niche specialization, population ecology and biogeochemical roles.
\end{abstract}

\footnotetext{
${ }^{1}$ Institute for Chemistry and Biology of the Marine Environment, University of Oldenburg, Oldenburg, Germany. ${ }^{2}$ Leibniz Institute DSMZ - German Collection of Microorganisms and Cell Cultures, Braunschweig, Germany. ${ }^{3}$ ICBMMPI Bridging Group for Marine Geochemistry, University of Oldenburg, Oldenburg, Germany. ${ }^{4}$ Centre for Marine Science and Innovation, University of New South Wales, Kensington, Australia. ${ }^{5}$ Singapore Centre for Environmental Life Sciences Engineering, Nanyang Technological University, Singapore, Singapore. ${ }^{6}$ Sydney Institute of Marine Science, Mosman, Australia. ${ }^{7}$ Braunschweig University of Technology, Braunschweig, Germany. ${ }^{8}$ Present address: Radboud University Nijmegen, Nijmegen, The Netherlands. ${ }^{9}$ Present address: Leibniz Institute of Freshwater Ecology and Inland Fisheries, Berlin, Germany. ${ }^{10}$ Present address: Western Sydney University, Hawkesbury, Australia. ${ }^{11}$ Present address: University of Sydney, Camperdown, Australia. ${ }^{12}$ Present address: University of Sunshine Coast, Sunshine Coast, Australia. ${ }^{13}$ Present address: Alfred Wegener Institute Helmholtz Centre for Polar and Marine Research, Bremerhaven, Germany. ${ }^{14}$ These authors contributed equally: Hanna Koch and Nora Germscheid. *email: matthias.wietz@awi.de
} 
Metabolic variability is a major driver of ecological differentiation within bacterial taxa, shaping adaptive strategies and hence the niche space of related strains ${ }^{1}$. With the increasing number of sequenced genomes, substantial functional diversity is being discovered among closely related strains ${ }^{2}$, with implications for bacterial species concepts ${ }^{3}$. This diversity can be investigated by interrogating the pangenome of a taxonomic group (i.e. their entire repertoire of core and variable genes) for genotypic variants with ecological implications ${ }^{4}$. Ecological differentiation within a taxon mainly relates to two flexible genomic categories: the accessory genome (shared by several strains) and the unique genome (restricted to individual strains). This variable repertoire is often encoded in genomic islands, hotspots of genetic exchange ${ }^{5}$ known to influence niche specialization in cyanobacteria, actinobacteria and roseobacters ${ }^{6-8}$. Flexible genomic islands, located at equivalent loci in different strains of the same taxon, can provide or replace genetic information and are important factors for intraspecific heterogeneity $\mathrm{y}^{9,10}$, for instance governing carbon utilization, siderophore production and pilus assembly ${ }^{11}$. These adaptive-evolutionary processes are often amplified by plasmids and other mobile genetic elements, driving horizontal gene transfer (HGT) and diversification on short time scales ${ }^{12-14}$. Bacterial adaptations can also relate to single-nucleotide exchanges via homologous recombination or mutations ${ }^{15,16}$.

Current approaches to species delineation, such as $16 \mathrm{~S}$ rRNA or core-genome phylogenies, do not always reflect the diversity of strain-specific ecological strategies. For instance, the analysis of $\sim 400$ Vibrio cholerae strains has revealed distinct intraspecific variability in genes mediating bioluminescence and colonization of zooplankton ${ }^{17}$. Closely related vibrios also show substantial divergence in polysaccharide degradation ${ }^{18}$ and particle colonization ${ }^{19}$. Comparable diversity has been observed for biosynthetic capacities within marine Salinispora spe$\operatorname{cies}^{20}$, with implications for strain-specific competitive abilities ${ }^{21}$. Also the degree of carbohydrate utilization can vary between strains of the same species ${ }^{22}$. Recently, these aspects have been extended to the metapangenomic dimension, revealing linkages of genomic and geographic variability among Prochlorococcus strains ${ }^{23}$.

The marine gammaproteobacterium Alteromonas macleodii is an excellent model to study the ecological consequences of strain-level variability, as multiple genome-sequenced isolates from diverse habitats and locations are available. The occupation of different niches ${ }^{24}$, varied interactions with other organisms $s^{25-27}$ and utilization of diverse substrates ${ }^{28,29}$ suggests the existence of functionally distinct entities within the A. macleodii species boundary, despite being $>99 \%$ identical on $16 \mathrm{~S}$ rRNA gene level. This notion is supported by the diverse flexible genome and a high degree of genetic exchange between $A$. macleodii and the "sister species" A. mediterranea ${ }^{13,30}$. Consequently, genomic islands and mobile genetic elements are major drivers of genetic and metabolic variability within Alteromonas, influencing surface-associated vs. free-living lifestyles ${ }^{31}$, exopolysaccharide production ${ }^{30}$, heavy metal resistance ${ }^{32}$ and polysaccharide utilization ${ }^{33}$. Notably, co-occurring Alteromonas strains have been postulated to colonize distinct microniches based on specific genomic features ${ }^{34}$ and competitive abilities ${ }^{35}$. For instance, A. mediterranea strains differ in motility and glucose utilization, potentially influencing patterns of co-occurrence or mutual exclusion ${ }^{35}$. Despite these ecological implications of genome plasticity, phenotypic and genomic variability have not been comprehensively linked in Alteromonas to date, largely because few putative traits have been experimentally verified.

The present study investigated strain-level phenotypic and genomic variability in twelve strains of $A$. macleodii with completely sequenced genomes, including three novel isolates from a Pacific Ocean transect. Supported by exometabolomic evidence and targeted physiological assays, we show how accessory and unique features shape ecological differentiation and result in "microdiversity" of phenotypic traits ${ }^{1,36}$. Co-culturing experiments linked these observations to strain-specific competitiveness, a factor that may influence ecophysiological roles and biogeographic distribution. The finding of diverse metabolic potentials within a narrow taxonomic range, whose members may co-occur or compete depending on prevailing conditions, contributes to the functional interpretation of bacterial species and populations. The shown intraspecific diversity in adaptive strategies helps understanding the widespread occurrence of $A$. macleodii in the oceans, with broader implications for bacterial population ecology and niche specialization.

\section{Results and Discussion}

This study combines genomic and phenotypic evidence to illuminate mechanisms of ecological differentiation within Alteromonas macleodii, a bacterium with widespread distribution and biogeochemical importance in the oceans $^{24}$. The study focused on twelve A. macleodii strains with closed genomes, featuring average nucleotide identities (ANI) of $96.5-99.9 \%$ and $16 \mathrm{~S}$ rRNA gene similarities of $>99 \%$ (Fig. 1; Table S1). Despite this clear association to a single genospecies ${ }^{37}$, underlined by 3002 core genes, we detected considerable strain-level diversity related to 1662 accessory and 1659 unique gene clusters (Table S2). This is consistent with the pronounced diversity of the flexible genome in A. macleodii and the "sister species" A. mediterranea, as described previously ${ }^{30}$. Intraspecific differences were highlighted by a diverse pan-exometabolome of 138 core, 1796 accessory and 2096 unique molecular masses secreted during late exponential growth (Table S3). In the following, we contextualize (pan)genomic and phenotypic evidence to characterize how genome plasticity shapes interactions with cyanobacteria and macroalgae, degradation of aromatics and polysaccharides, chemical communication, iron acquisition, and intraspecific competition. These insights expand structural-genomic and evolutionary aspects of the Alteromonas pangenome $\mathrm{e}^{30,32,34,38,39}$ by ecological perspectives on niche specialization, competitive abilities and biogeography.

Plasmids and genomic rearrangements. As niche specialization is often mediated by mobile genetic elements ${ }^{40}$, we first characterized occurrence and function of plasmids. Eight out of twelve A. macleodii strains, including MIT1002 and EZ55 whose genomes were re-sequenced and closed herein, were found to contain a plasmid (Figs. 1, S1). Synteny of plasmids from A. macleodii Te101 and A. mediterranea DE1 corroborates the role of plasmids for niche specialization within and across species boundaries ${ }^{13,41}$. 


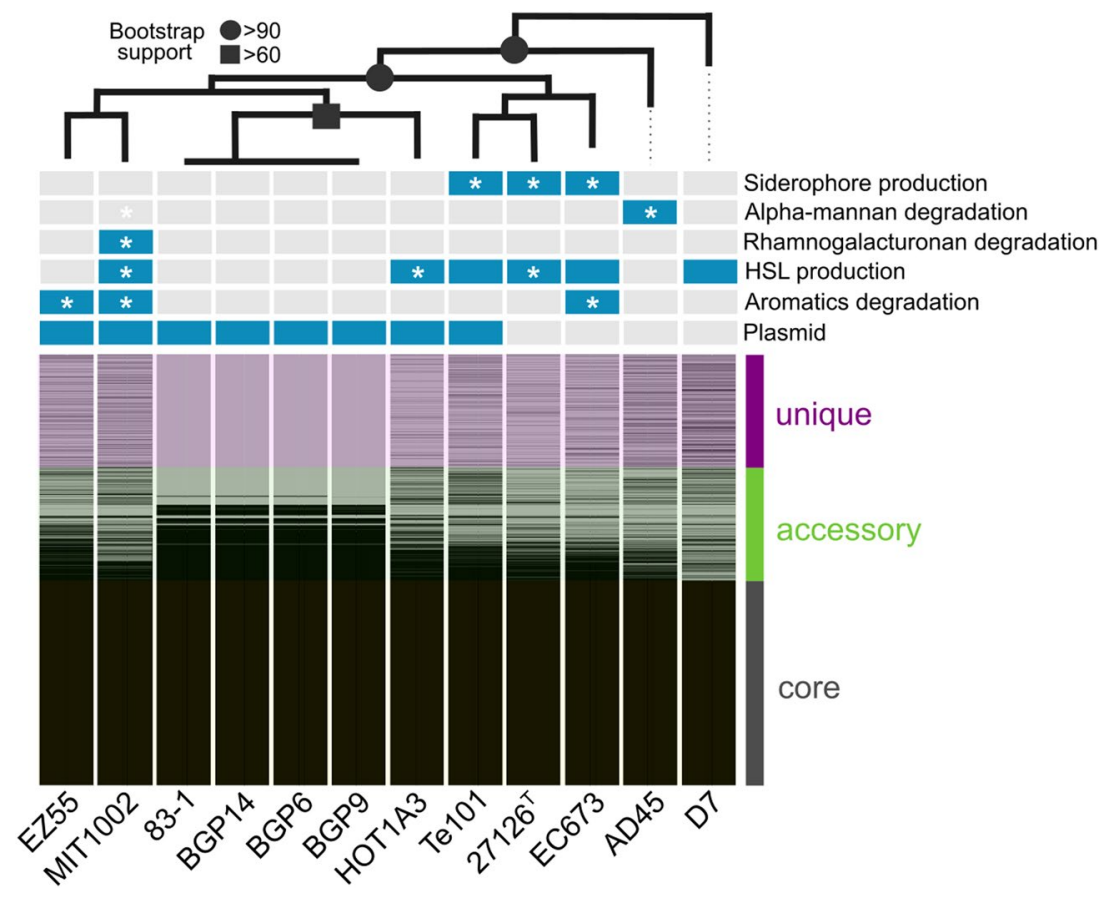

Figure 1. Maximum-likelihood phylogeny and pangenome structure of Alteromonas macleodii, showing presence (blue) and absence (gray) of specific genomic features. Phylogenetic analysis was based on 92 singlecopy housekeeping genes identified using the UBCG pipeline ${ }^{119}$. Asterisks designate phenotypic features experimentally verified in the present study. Bootstrap support values are indicated by symbols; unlabeled branches have $<50 \%$ support.

The plasmids of six strains display a similar functional profile, harboring metal resistance and [NiFe] hydrogenase cassettes (Fig. 2A) that have been described in Alteromonas before ${ }^{42,43}$ and provide increased resistance compared to strains lacking these cassettes ${ }^{43}$. As homologous cassettes in A. mediterranea are encoded in a chromosomal genomic island ${ }^{30,32,44}$, plasmids possibly mediate their transfer between Alteromonadales ${ }^{13}$. Notably, number and arrangement of cassettes differed between strains (Fig. 2A), which may result in varying expression levels and hence different resistance profiles ${ }^{45}$. In strain MIT1002, hydrogenase and resistance cassettes have been inserted into the chromosome, and a unique chemotaxis-related plasmid has been acquired (Fig. 2B). This event may enhance chemosensory abilities and provide a competitive advantage to access nutrient patches ${ }^{46}$.

The plasmid of strain EZ55 harbors a unique $20 \mathrm{~Kb}$ insert, enabling aerobic degradation of the aromatic hydrocarbons toluene and xylene (Figs. 2; S2) as rarely described in marine microbes to date ${ }^{47,48}$. The insert is overall homologous to the TOL plasmid from Pseudomonas putida (Fig. 2A), a hydrocarbon-degrading

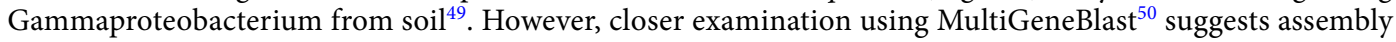
during separate horizontal transfer events. Specifically, the downstream section (locus tags 04282-04290) has highest similarity to TOL plasmids from Pseudomonas strains, with amino acid identities between 70 to $86 \%$ (Fig. 3A). In contrast, the upstream section including the catechol meta-cleavage pathway (locus tags 0424804260) has highest similarity to homologous clusters in Marinobacter followed by Pseudomonas spp., with amino acid identities between 52 and 98\% (Fig. 3A). Considering multiple adjacent transposases and recombinases (locus tags 04244, 04264, 04266, 04267, 04270, 04273, 04279, 04291) and the fact that Alteromonas, Pseudomonas and Marinobacter co-occur during oil spills where toluene and xylene are present ${ }^{51}$, we hypothesize exchange of these clusters at contaminated sites. Alternatively, Marinobacter might constitute a "vehicle" between soil and seawater due to its occurrence in saline lakes und intertidal areas ${ }^{52}$ and known acquisition of aromatic-degrading genes from Pseudomonas ${ }^{53}$. Considering the common association of Marinobacter spp. with phototrophs ${ }^{54,55}$, the cluster might likewise enable degradation of ecologically more relevant aromatics from cyanobacteria, e.g. derivatives of benzoate or cinnamate ${ }^{56}$.

Alteromonas and Prochlorococcus. In addition to plasmids, ecological differentiation also relates to varying abilities for microbial interactions ${ }^{57}$. In this context, strains MIT1002 and EZ55 are naturally associated with Prochlorococcus cyanobacteria, to whom they establish mutualistic relationships by alleviating oxidative stress or nutrient limitation during extended periods of darkness ${ }^{58-61}$. Here, we demonstrate additional features that may support their co-existence. Specifically, only MIT1002 harbors a gene cluster encoding the potential for phenol metabolization (Figs. 4A; S2). This ability appears ecologically relevant considering upregulation of phenol hydroxylases in co-culture with Prochlorococcus (Table S4 with data from ${ }^{62}$ ), the common production of phenolics by cyanobacteria ${ }^{63}$, and presence of a homologous gene cluster in Marinobacter algicola with comparable association to phototrophs ${ }^{54}$. The Alteromonas-Prochlorococcus interplay may be further strengthened by metabolic interrelations, as FT-ICR-MS revealed that MIT1002 and EZ55 secrete ecologically relevant exometabolites 


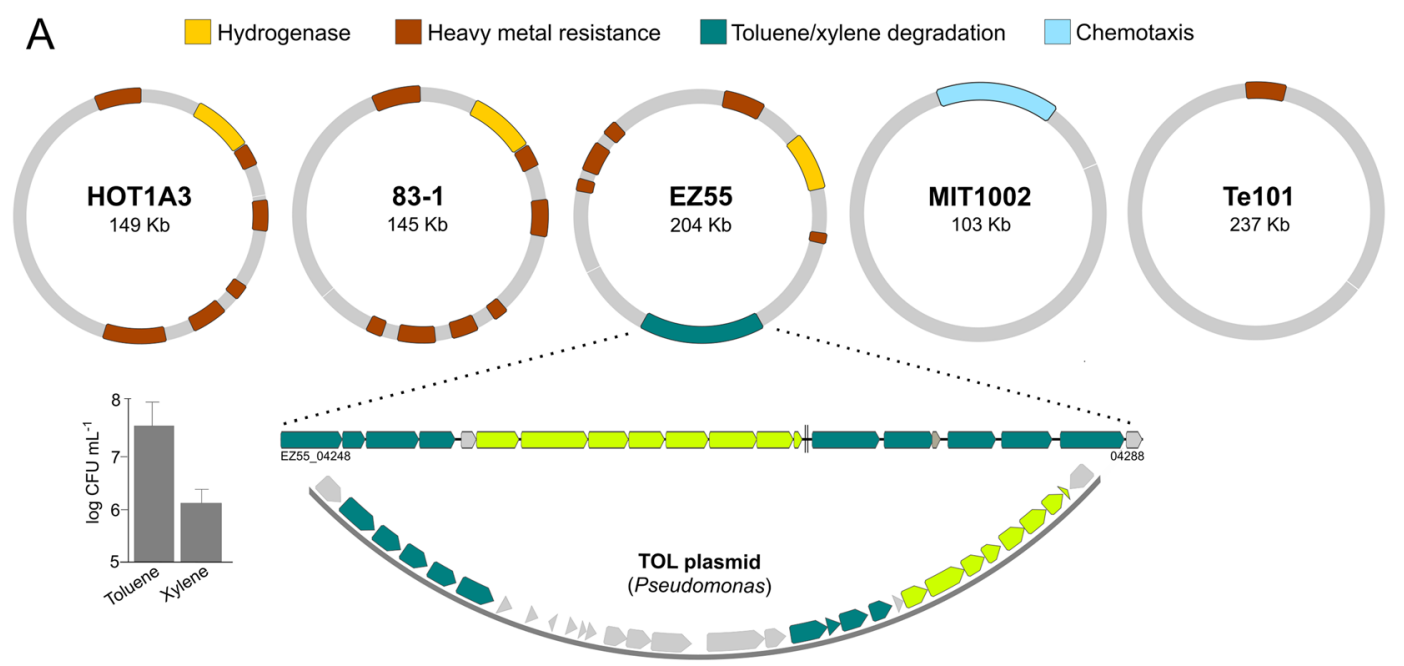

B
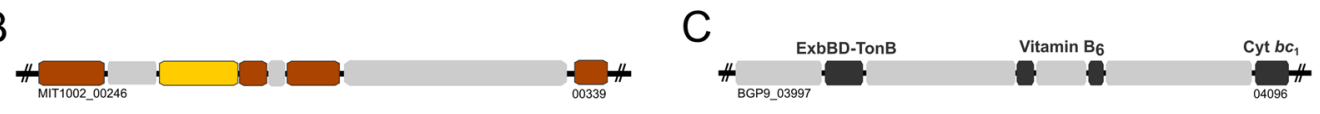

Figure 2. Structural diversity of plasmids in Alteromonas macleodii. (A) Functionally similar plasmids in strains HOT1A3, 83-1 and EZ55 encoding hydrogenase and heavy metal resistance cassettes, however with different organization. The plasmid of EZ55 furthermore contains a unique insertion syntenic to the Pseudomonas TOL plasmid (blue-green: toluene/xylene hydroxylases and transporters; green: catechol metacleavage pathway; gray: non-homologous genes) allowing growth with toluene and xylene as sole carbon source (insert). The plasmid of strain Te101 is structurally different and encodes only one resistance cassette. (A,B) Strain MIT1002 harbors a unique chemotaxis-related plasmid, whereas an $80 \mathrm{~Kb}$ region encoding hydrogenase and resistance cassettes has been translocated to the chromosome. (C) Strain BGP9 features a chromosomeplasmid translocation of a $90 \mathrm{~Kb}$ region harboring a TonB/ExbBD membrane system, a cytochrome $b c_{1}$ complex and vitamin $\mathrm{B}_{6}$ synthesis genes.

(Table 1). Secretion of methyl-tryptophan and methyl-indolepyruvate may explain the differential regulation of tryptophan biosynthesis in Prochlorococcus when co-cultured with A. macleodii ${ }^{64,65}$, especially under restricted photosynthesis ${ }^{59}$. Secretion of asparagine and glutamine (Table 1) indicates exchange of further amino acids, coincident with upregulation of related importers in Prochlorococcus when co-cultured ${ }^{64}$. Possible cross-feeding is supported by the potential for mixotrophy ${ }^{66}$ and considerable usage of exogenous amino acids ${ }^{67}$ in environmental Prochlorococcus assemblages. Hence, these compounds are possible drivers of varied prokaryotic ${ }^{68,69}$ but $^{2}$ also interkingdom interactions, as A. macleodii can likewise counteract amino acid deficiency in microalgae ${ }^{25}$.

Comparison with prior transcriptomic data ${ }^{59}$ showed that interactions of MIT1002 with Prochlorococcus involve several unique genes (Table S4). For instance, differential regulation of unique chemotaxis-, motility- and biofilm-related genes in co-culture may strengthen physical associations $\mathrm{s}^{70}$ whereas upregulation of a phytase gene might enhance phosphorus acquisition ${ }^{71}$. Overall, the array of interactive features suggests that MIT1002 and EZ55 are adapted to a mutualistic niche with Prochlorococcus, a relevant notion considering the cyanobacterium's reduced metabolic repertoire and importance for biogeochemical cycles ${ }^{72,73}$.

Alteromonas, macroalgae and algal polysaccharides. We herein isolated A. macleodii strains BGP6, BGP9 and BGP14 from alginate-supplemented microcosms in the south, equatorial and north Pacific Ocean (Table S1) using analogous procedures that yielded the alginolytic strain A. macleodii 83-1 from the Atlantic ${ }^{33}$. Strikingly, the new isolates and strain 83-1 are clonal, featuring only four polymorphisms in 4,801,369 core sites despite being isolated over wide geographic and temporal scales. These observations resemble the isolation of $A$. mediterranea strains with less than 100 polymorphisms from distant locations and years apart ${ }^{30,38}$. In addition, two A. australica strains with $99 \%$ ANI have been retrieved from opposite global locations ${ }^{44}$, illustrating that highly similar Alteromonas spp. are widely distributed over time and space.

The four clonal $A$. macleodii strains encode numerous carbohydrate-active enzymes (CAZymes) and other enzymes involved in carbohydrate-related KEGG categories (Fig. S3A; Table S2), enabling the degradation of various algal polysaccharides ${ }^{74}$ and indicating association with plants ${ }^{75}$. To examine whether these features trigger direct interactions with algae, $A$. macleodii 83-1 was incubated with tissue from the marine macroalga Ecklonia radiata, which contains $>50 \%$ alginate and hence a preferred substrate ${ }^{33}$. However, no significant tissue degradation was observed (Fig. S3B) although epibiotic bacteria cause visible digestion of Ecklonia and other macroalgae $^{76-78}$. These observations suggest that $A$. macleodii has limited abilities to attack macroalgal tissue, and potentially utilizes polysaccharide exudates released directly by the macroalga ${ }^{74}$ or by co-metabolizing bacteria ${ }^{18}$. This proposed lifestyle is supported by low Alteromonas abundances on wild macroalgae ${ }^{79}$. Alternatively, colonization might occur in a neutral manner, comparable to other Alteromonas spp. with a similar CAZyme profile ${ }^{80}$. 
A

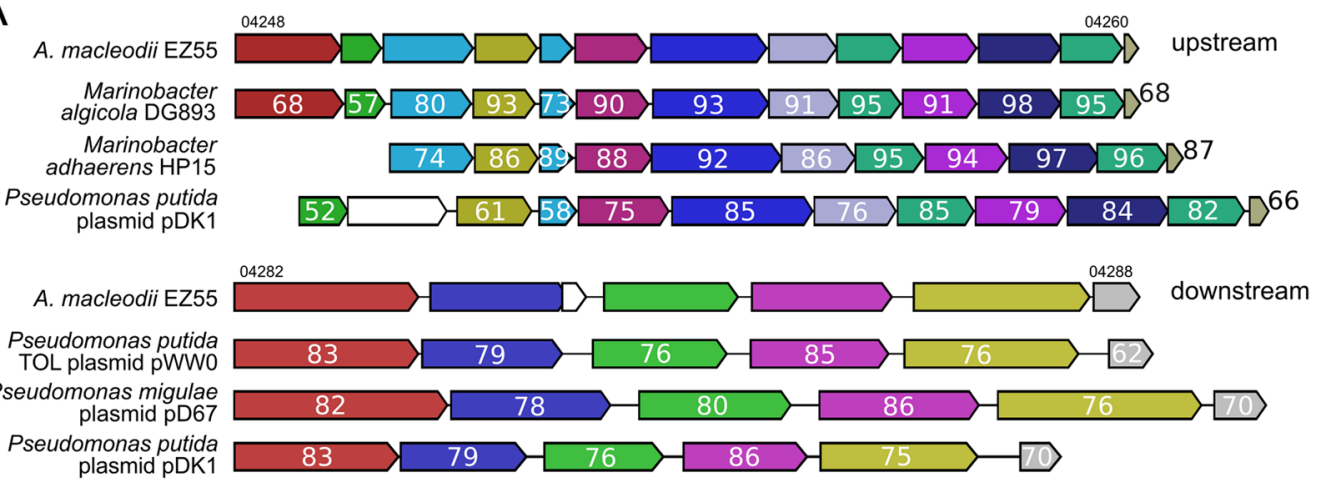

B

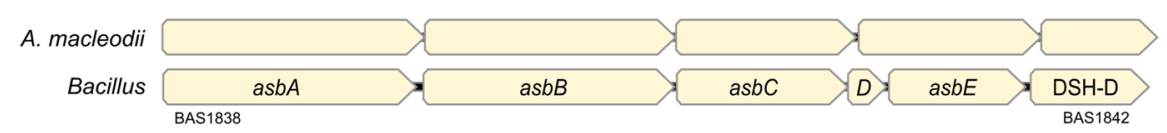

C

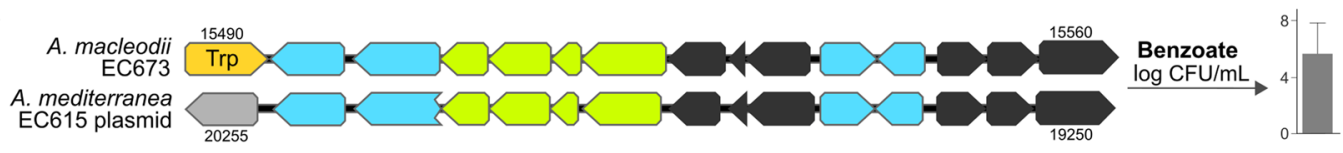

Figure 3. Comparative analysis of selected gene clusters in Alteromonas macleodii and other bacteria. (A) Gene cluster for toluene/xylene degradation in strain EZ55 plus closest relatives of upstream (locus tags 04248-04260) and downstream (04282-04288) cluster sections. Colors illustrate homologs as determined by MultiGeneBlast, with numbers designating \% amino acid similarities. (B) Homology of the siderophore-encoding cluster of strains ATCC27126 ${ }^{\mathrm{T}}$, EC673 and Te101 with the petrobactin operon $a s b A B C D E$ plus adjacent dehydroshikimate dehydratase (DHS-D) from Bacillus spp. (C) Gene cluster for benzoate degradation in strain EC673, encoding benzoate dioxygenases (green), the catechol ortho-cleavage pathway (black) and transporters/regulators (blue), allowing growth with benzoate as sole carbon source (right insert). A homologous cluster is encoded on the plasmid of $A$. mediterranea EC615. Trp: transposase; gray: non-homologous gene.

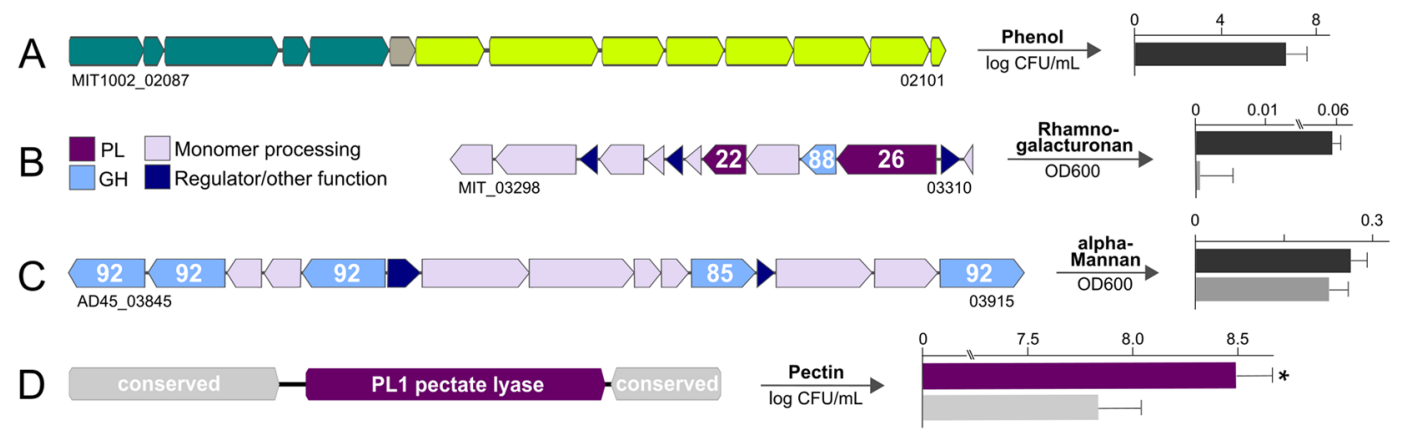

Figure 4. Features of Alteromonas macleodii relating to interactions with cyanobacteria and macroalgae. (A) Unique gene cluster in strain MIT1002 encoding phenol hydroxylases (blue-green) and the catechol metacleavage pathway (green), allowing growth with phenol as sole carbon source. (B,C) Unique polysaccharide utilization loci in strains MIT1002 and AD45 allowing growth with rhamnogalacturonan and alpha-mannan as sole carbon source (MIT1002: dark gray, AD45: light gray). Numbers designate encoded glycoside hydrolase and polysaccharide lyase families. (D) Several strains encode an additional PL1 pectate lyase within a conserved region, enhancing growth with pectin as sole carbon source (purple: strain 83-1 with additional PL1; gray: strain HOT1A3 without). $* p<0.05$.

Considering nucleotide substitution rates of ca. $10^{-8}$ per site/year in related Gammaproteobacteria ${ }^{81}$, the four clonal strains probably diverged only recently followed by rapid geographic spread, comparable to Phaeobacter strains from the same Pacific transect ${ }^{82}$. However, some features illustrate the beginning of differentiation. In $\mathrm{BGP} 9$, a $91 \mathrm{~Kb}$ region harboring a TonB/ExbBD membrane system and vitamin $\mathrm{B}_{6}$ synthesis genes was translocated from chromosome to plasmid (Fig. 2C), which may influence iron and vitamin metabolism ${ }^{83,84}$. The transposed region also harbors the strain's sole cytochrome $b c_{1}$ complex, although essential genes are uncommon on plasmids ${ }^{85}$. At an estimated plasmid loss of $\sim 10^{-3}$ per cell and generation ${ }^{86}$, this event may pose a considerable risk for survival. 


\begin{tabular}{|l|l|l|}
\hline Exact mass $(\mathbf{D a})$ & Predicted compound & Detected in \\
\hline 216.066647 & methyl-indolepyruvate & MIT1002 \\
\hline 217.098241 & methyl-tryptophan & EZ55 \\
\hline 131.046208 & asparagine & EZ55 \\
\hline 145.061869 & glutamine & EZ55 \\
\hline 198.186345 & dodecanamide (fatty acid moiety of 3-oxo-C12-HSL) & MIT1002 \\
\hline 296.186680 & N-3-oxododecanoyl-homoserine lactone (3-oxo-C12-HSL) & HOT1A3 \\
\hline 198.113576 & N-hexanoyl-L-homoserine lactone (C6-HSL) & 27126 $^{\text {T }}$ \\
\hline
\end{tabular}

Table 1. Selected exometabolites of Alteromonas macleodii strains.

Specific adaptations to algal polysaccharide degradation were also found in strains MIT1002 and AD45, mediated by unique polysaccharide utilization loci (PUL) ${ }^{87}$. Specifically, only MIT1002 harbors a PUL encoding PL22 and PL26 polysaccharide lyases, a GH88 rhamnogalacturonyl hydrolase and several rhamnose-processing genes, allowing growth with rhamnogalacturonan as sole carbon source (Fig. 4B). A PL26-GH88 pair also occurs in the rhamnogalacturonan-degrading flavobacterium Gramella flava $^{88}$, indicating co-functionality towards rhamnose-rich polysaccharides. As rhamnogalacturonan is present in widespread marine macroalgae ${ }^{74}$, degradative abilities may strengthen associations between MIT1002 and phototrophs. Homologous PUL in A. australica with $80 \%$ nucleotide identity (data not shown) demonstrates independent acquisition of these genes by other Alteromonas species, comparable to PUL targeting ulvan from green algae ${ }^{89,90}$. Strain AD45 harbors a unique PUL encoding GH85 and GH92 mannosidases and grows with alpha-mannan as sole carbon source (Fig. 4C), but comparable growth of MIT1002 indicates that mannosidase activity also occurs via other encoded GHs (Fig. S3A). Opposed to mannan-degrading marine flavobacteria ${ }^{91}$, strain AD45 does not encode sulfatases and may hence primarily target terrestrial mannans, corresponding to its coastal origin ${ }^{92}$ and the lower degree of sulfatation in terrestrial polysaccharides ${ }^{93}$. A speculative link relates to the isolation of AD45 from the vicinity of aquaculture facilities, where mannan oligosaccharides are increasingly used as feed additive ${ }^{94}$. Overall, presence in diverse terrestrial and aquatic bacteria (Fig. S3C) suggests the PUL as a widespread niche-defining feature.

Finally, we found that adaptation towards algal polysaccharide degradation is also linked to numerical variation in CAZymes, in context of gene dosage effect and substrate affinity ${ }^{18}$. Specifically, A. macleodii strains that encode three PL1 pectate lyases grow significantly better on pectin than strains with only two lyases (Figs. 4D; S3A). Enrichment of the third lyase in the exoproteome of strain $83-1^{74}$ suggests a role in extracellular substrate recognition and initial hydrolysis. Enhanced degradation through higher lyase numbers is consistent with observations in Zobellia galactanivorans, a common macroalgal associate and proficient polysaccharide degrader ${ }^{78}$. Overall, the patchy distribution of rhamnogalacturonan, mannan and pectin degradation discriminates $\mathrm{A}$. macleodii into specific "polysaccharide utilization types" with distinct ecophysiological roles ${ }^{95}$.

Cellular communication. Ecological differentiation can also coincide with the potential to coordinate behavior at population level. In this context, we found that $A$. macleodii strains vary in their ability to synthesize homoserine lactones (HSL) for intraspecific communication via quorum sensing ${ }^{96}$. Two gene variants encoding $\mathrm{N}$-acyl amino acid synthase occur in A. macleodii (Fig. 5A), but masses corresponding to C6-HSL, 3-oxo-C12-HSL and dodecanamide (the fatty acid moiety of 3-oxo-C12-HSL) were only detected in exometabolomes of strains $27126^{\mathrm{T}}$, HOT1A3 and MIT1002 (Table 1). The restriction of HSL production to these strains is supported by antismash ${ }^{97}$, which only predicts their sequence variant as functional synthase (Table S1). Accordingly, the autoinducer domain of producers and non-producers has $<80 \%$ sequence identity (data not shown). Synthase sequences of $27126^{\mathrm{T}}$, HOT1A3 and MIT1002 contain different substitutions (Fig. 5A), which potentially explains the observation of HSLs with differing chain lengths ${ }^{98}$. HSLs were only detectable using highly sensitive FT-ICR-MS but not standard bacterial monitor assays ${ }^{99}$, but HSLs can influence chemical interactions and surface attachment even at low concentrations ${ }^{96,100}$. Intraspecific HSL diversity has also been described among symbiotic Vibrio ${ }^{101}$, suggesting variable potential for chemical communication as common discriminator of closely related strains.

Iron acquisition. Successful niche colonization also depends on efficient acquisition of limiting micronutrients, including iron ${ }^{102}$. In this context, only strains $27126^{\mathrm{T}}$, EC673 and Te101 harbor a gene cluster for siderophore synthesis with demonstrated iron-scavenging activity (Fig. 5B), likely providing an advantage during iron limitation ${ }^{103}$. The gene cluster is homologous to the petrobactin operon of Bacillus spp. (Fig. 3B; 35\% amino acid identity) and also occurs in other marine bacteria, suggesting broad ecological relevance ${ }^{104}$. In strain EC673 from the English Channel, the siderophore might support growth with benzoate as sole carbon source (Figs. 3C, S2) by counteracting iron limitation of benzoate breakdown ${ }^{105}$. This scenario could be advantageous considering the anthropogenic input of benzoate in its original habitat ${ }^{106}$. The benzoate cluster is located in a genomic island ${ }^{32}$ and flanked by a transposase, underlining the importance of flexible loci for phenotypic variability. Notably, also A. mediterranea EC615 from the English Channel harbors the benzoate-related cluster (Fig. 3C), but encoded on a plasmid ${ }^{38}$. These observations indicate common occurrence and exchange of these genes via mobile genetic elements in habitats where certain chemicals may prevail.

Strain MIT1002 harbors a truncated siderophore cluster, where synthases have been separated by metal-resistance cassettes during the translocation from plasmid to genome (see above). This integration 


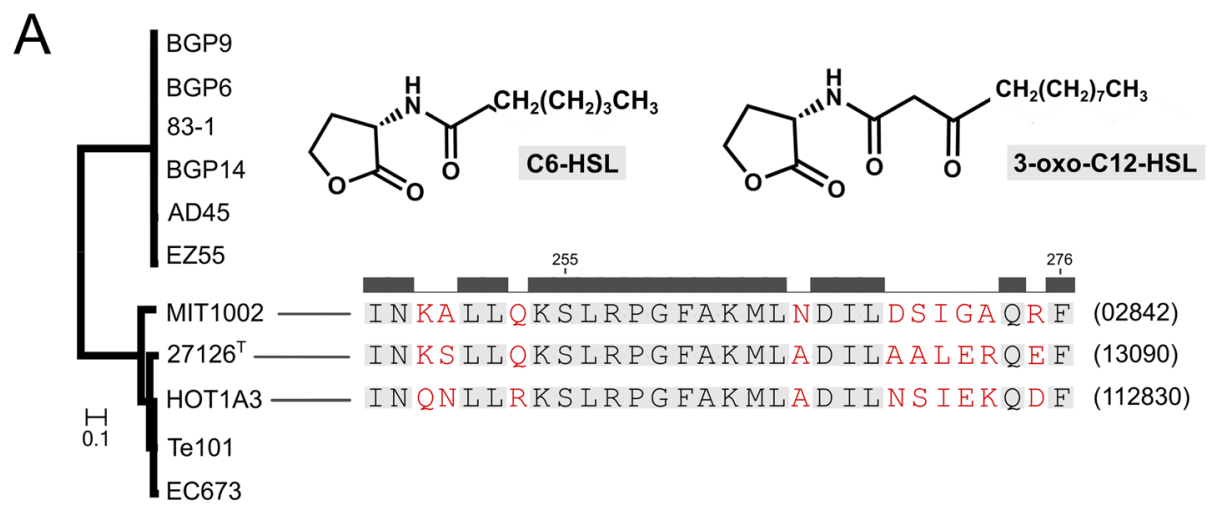

B

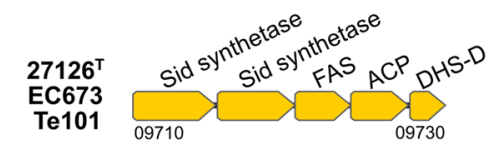

MIT1002
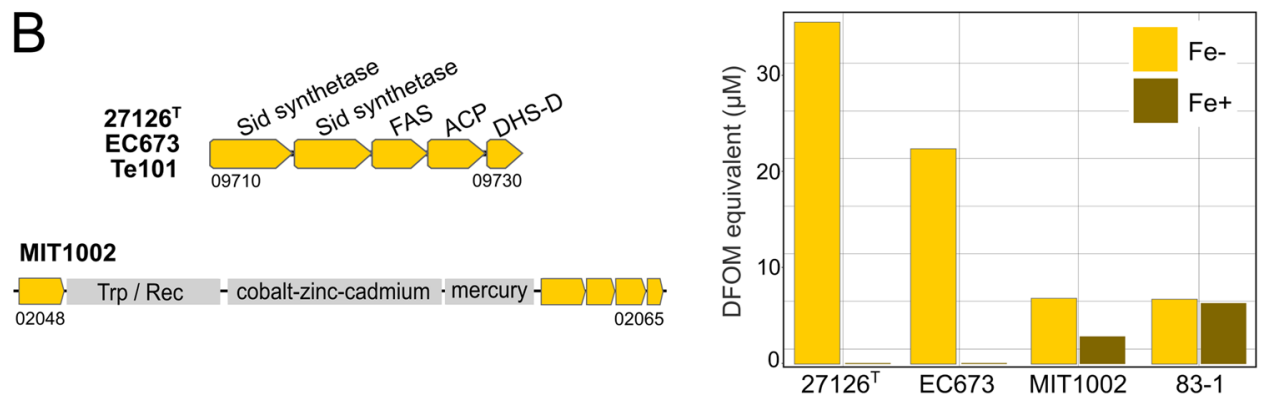

Figure 5. Cellular communication and iron acquisition in Alteromonas macleodii. (A) Phylogenetic analysis reveals two sequence variants of $\mathrm{N}$-acyl amino acid synthase in producers (lower) and non-producers (upper clade) of homoserine lactones (HSL). Accordingly, molecular masses relating to C6-HSL and 3-oxo-C12HSL were only secreted by strains $27126^{\mathrm{T}}$, MIT1002 and HOT1A3 (see Table 1). Strain-specific amino acid substitutions (red) may explain differential HSL production (synthase locus tags in parentheses). (B) Gene cluster unique to strains $27126^{\mathrm{T}}$, EC673 and Te101 encoding a functional siderophore (locus tags from type strain), with iron-scavenging activity under iron-deplete $(\mathrm{Fe}-)$ but not iron-replete $(\mathrm{Fe}+)$ conditions in relation to deferoxamine mesylate (DFOM) standard. MIT1002 harbors a nonfunctional cluster after insertion of gene cassettes for cobalt-zinc-cadmium and mercury resistance. Weak signals in MIT1002 and negative control 83-1 under both conditions signify iron-unrelated effects. Sid: siderophore; FAS: fatty acid synthase; ACP: acyl carrier protein; DHS-D: 3-dehydroshikimate dehydratase; Trp: transposase; Rec: recombinase.

abolished iron-scavenging activity (Fig. 5B), showing that genetic exchange and restructuring of genomic islands can also be disadvantageous.

Implications for intraspecific interactions and biogeography. To address broader eco-evolutionary implications, we asked whether strain-level variability affects population dynamics, competitive abilities and biogeographic distribution ${ }^{107,108}$. For instance, it is known that natural populations of $A$. macleodii can be dominated by specific strains through competitive exclusion ${ }^{34,109}$. To evaluate these aspects, three $A$. macleodii strains with comparable growth in monoculture (Fig. S4) were co-cultured with glucose as sole carbon source, and individual population sizes determined by quantitative PCR of unique genes (Table S5). The tripartite co-culture was dominated by strain MIT1002, which outcompeted both $83-1$ and $27126^{\mathrm{T}}$ over a period of $24 \mathrm{~h}(p<0.01)$. Furthermore, strain $83-1$ outcompeted $27126^{\mathrm{T}}$ in late exponential phase $(p<0.001)$ (Fig. 6A). Comparable intraspecific differences were also observed in A. mediterranea, where greater competitive abilities coincided with higher motility ${ }^{35}$. The putative importance of motility in microbial interactions is supported by upregulation of related genes in MIT1002 when co-cultured with Prochlorococcus ${ }^{62}$.

Higher competitiveness of MIT1002 on glucose may provide an advantage in the environment, as glucose is one of the major marine carbohydrates ${ }^{110}$. Accordingly, MIT1002 showed a wider geographic distribution in TARA Ocean metagenomes (Fig. 6B, Table S6), indicating linkages between metabolic abilities and biogeography. Contact with diverse microbiota in different locations may also explain why unique genes of MIT1002 have been acquired from a wider taxonomic range (Fig. 6C; Table S7). These patterns may be amplified by association with Prochlorococcus, considering the wide occurrence of the cyanobacterium and higher genetic exchange in host-associated niches ${ }^{111,112}$. In contrast, $27126^{\mathrm{T}}$ has been isolated from oligotrophic waters with less biological activity and genetic exchange ${ }^{113}$, and lower growth efficiency on glucose may indicate a $k$-strategist lifestyle. Future co-culturing systems could address how co-existence or competitive exclusion proceed in more complex ecological scenarios, for instance pioneer-scavenger relationships during polysaccharide degradation ${ }^{18}$. 


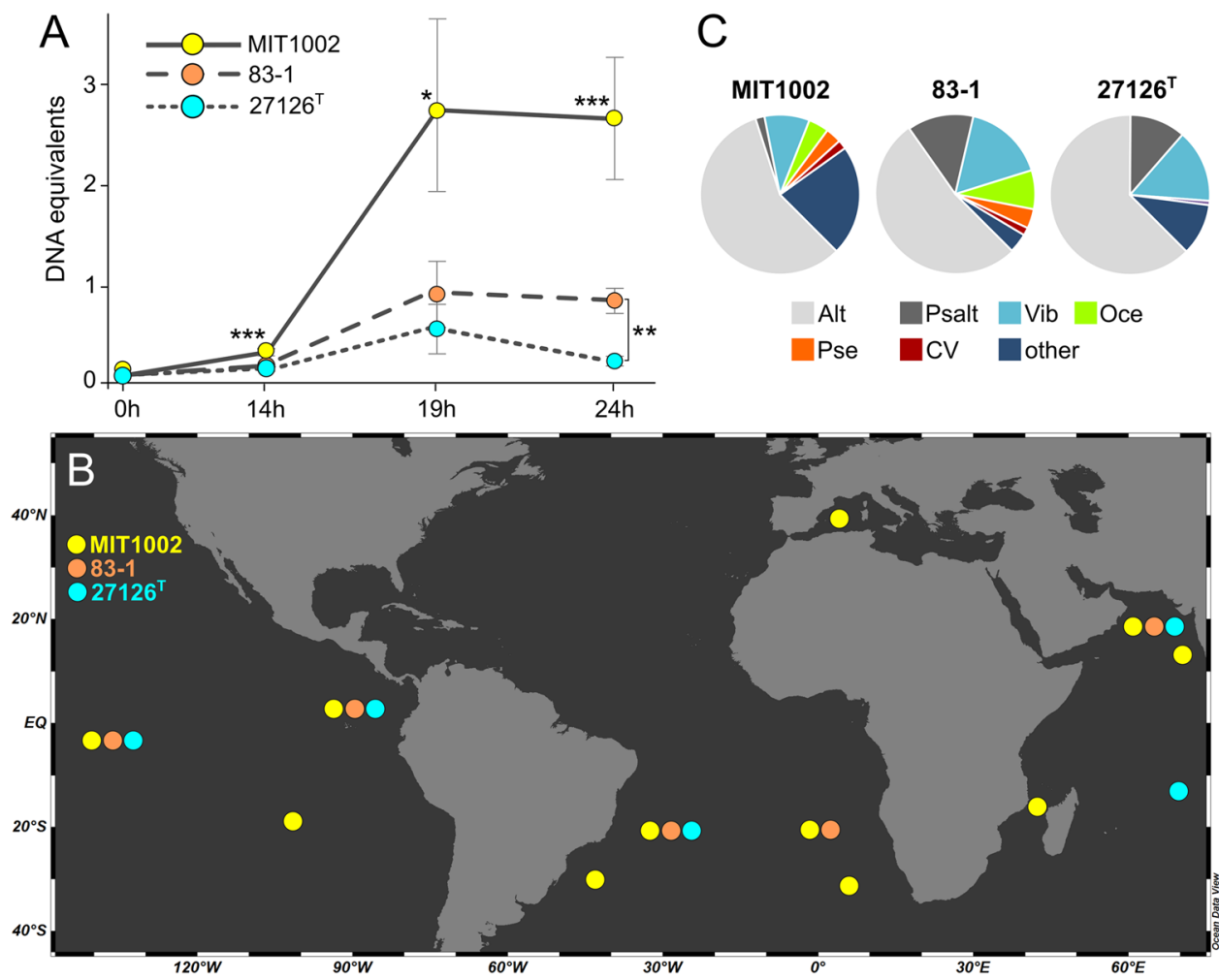

Figure 6. Ecological implications of strain-specific variability in Alteromonas macleodii. (A) Varying competitiveness of strains MIT1002, 83-1 and $27126^{\mathrm{T}}$ in a tripartite co-culture, determined by quantitative PCR of unique genes $(* p<0.01 ; * p<0.001 ; * * p<0.0001)$. (B) Occurrence of strains MIT1002, 83-1 and $27126^{\mathrm{T}}$ in TARA Ocean metagenomes based on BLAST of unique genes (see Table S6 for details). (C) Closest relatives of unique genes from strains MIT, 83-1 and $27126^{\mathrm{T}}$ based on BLAST against NCBI RefSeq. Alt: Alteromonadaceae; Psalt: Pseudoalteromonadaceae; Vib: Vibrionaceae; Oce: Oceanospirillaceae; Pse: Pseudomonadaceae; CV: Cellvibrionales (see Table S7 for details).

\section{Conclusions}

Here, we extend existing knowledge on (pan)genome evolution and structure in Alteromonas by functional perspectives on genome plasticity in twelve $A$. macleodii strains. The shown range of ecological strategies demonstrates that single genospecies can encompass considerable diversity of adaptive features, underlining the importance of polyphasic studies that link bacterial genotypes and phenotypes ${ }^{114}$. The "ecological microdiversity" among strains with $>99 \% 16$ S rRNA gene identity should be emphasized in microbial diversity studies, which are only beginning to explore the extent of fine-scale variability in natural communities ${ }^{36}$. Notably, phylogenetic relationships only partially corresponded to ecological similarity, illustrated by the patchy distribution of niche-defining metabolic features. Hence, in line with common recombination and genetic exchange ${ }^{30}, A$. macleodii appears to perform constant "pathway sampling" that has not (yet) manifested in divergence of specific clades. Metabolic versatility probably facilitates flexible responses to environmental conditions, contributing to the feast-and-famine lifestyle and widespread occurrence of this marine bacterium ${ }^{24,30}$. Sequencing of additional genomes may reveal whether strain-specific abilities translate to the existence of phylogenetic clades with distinct ecological boundaries, corresponding to larger eco-evolutionary concepts ${ }^{1,115,116}$. Our functional-ecological interpretation of the A. macleodii pangenome, illustrating the extent of eco-genomic differentiation within bacterial species, has broader implications for niche specialization, microbial interactions and biochemical roles of marine bacteria.

\section{Materials and Methods}

Isolation and sequencing of Alteromonas macleodii strains. Strains BGP6, BGP9 and BGP14 were isolated from alginate-enriched seawater from the south, equatorial and north Pacific Ocean on expedition SO248 with RV Sonne ${ }^{117}$. The genomes of BGP strains, MIT1002 and EZ55 were sequenced de novo using PacBio II technology (Supplementary Methods). In addition, a number of published closed genomes were analyzed (Table S1).

Pangenomic and phylogenetic analyses. Core, accessory and unique genes (Table S2) were identified using anvio v5. $2^{118}$ following the pangenome workflow of Delmont and coworkers ${ }^{23}$ with minbit parameter 0.5, MCL inflation parameter 10, Euclidean distance and Ward linkage, and NCBI-BLASTp for sequence similarity analysis (see Supplementary Methods for details). For phylogenetic analysis, 92 single-copy core genes (https://help.ezbiocloud.net/ubcg-gene-set) were identified, extracted and aligned using the UBCG pipeline ${ }^{119}$ with Alteromonas stellipolaris LMG $21861^{\mathrm{T}}$ as outgroup. The alignment was manually checked and submitted to 
W-IQ-TREE ${ }^{120}$ for calculating a maximum-likelihood phylogeny with 1000 bootstrap replicates and the GTR $+\mathrm{G}$ model determined by jModeltest $2^{121}$. Average nucleotide identities, polymorphic sites and a 16S rRNA gene similarity matrix were calculated using enveomics ${ }^{122}$, ParSNP/Gingr ${ }^{123}$ and BioEdit ${ }^{124}$, respectively. Biosynthetic gene clusters and prophages were predicted using antiSMASH $4.0^{97}$ and PHASTER ${ }^{125}$, respectively. CAZymes were predicted using dbCAN2 ${ }^{126}$ and abundances visualized using R package pheatmap ${ }^{127}$, only considering HMM hits with e-value $<10^{-23}$ and $>80 \%$ query coverage. Genes were assigned to KEGG categories using KAAS and GhostKoala ${ }^{128,129}$. Annotations were checked using UniProtKB/Swiss-Prot ${ }^{130}$ and Pfam ${ }^{131}$. Amino acid sequences of homoserine lactone synthases were aligned using MAFFT ${ }^{132}$ followed by maximum-likelihood phylogeny using MEGA $7^{133}$ with 1000 bootstrap replicates and the $\mathrm{LG}+\mathrm{G}$ model determined by ProtTest ${ }^{134}$. Statistical analyses were done in $\mathrm{R}$ v3.5.2 $2^{135}$ within RStudio (https://www.rstudio.com). Reported significances refer to Wilcoxon rank-sum tests $(p<0.05)$.

Exometabolomics. All cultivations were done in triplicate using SWM seawater minimal medium ${ }^{136}$. Each replicate was inoculated at $1 \%(\mathrm{v} / \mathrm{v})$ with precultures grown in $10 \mathrm{~mL} \mathrm{SWM}+0.1 \%$ glucose for $24 \mathrm{~h}$ at $20^{\circ} \mathrm{C}$ and $140 \mathrm{rpm}$ (washed twice with sterile SWM and diluted to OD600 of 0.1 before inoculation). For exometabolomics, nine strains were inoculated in $50 \mathrm{~mL} \mathrm{SWM}+0.1 \%$ glucose at $0.5 \%(\mathrm{v} / \mathrm{v})$ in triplicate. After incubation at $20^{\circ} \mathrm{C}$ and $140 \mathrm{rpm}$ until late exponential phase, a $20 \mathrm{~mL}$ subsample from each replicate was centrifuged for $20 \mathrm{~min}$ at $3500 \mathrm{~g}$ and $4{ }^{\circ} \mathrm{C}$. In addition, three sterile media blanks were incubated and processed in the same manner. Exometabolites were purified from supernatants using solid phase cartridges ${ }^{137}$ followed by ultrahigh-resolution mass spectrometry ${ }^{138,139}$ on a $15 \mathrm{~T}$ Solarix Fourier transform ion cyclotron resonance mass spectrometer (FT-ICR-MS) in negative mode (Supplementary Methods). Only peaks present in two biological replicates were considered, and only if detected in technical duplicates measured per replicate. Furthermore, spectra were calibrated and denoised using strict procedures to ensure that only bacterial metabolites were evaluated (Table S3). Tentative identification of masses was done using databases MetaCyc ${ }^{140}$ and KEGG Compounds via R package KEGGREST ${ }^{141,142}$

Degradation of different substrates. Degradation of specific carbon sources was tested in SWM supplemented with phenol (final concentration $0.5 \mathrm{mM})$, toluene $(1 \mathrm{mM})$, xylene $(1 \mathrm{mM})$, sodium benzoate $(2 \mathrm{mM})$, alpha-mannan (Carbosynth YM63069; 0.1\% w/v), rhamnogalacturonan (Megazyme P-RHAM1; 0.1\% w/v), or pectin (Fluka $76282 ; 0.1 \% \mathrm{w} / \mathrm{v}$ ). Cultures were inoculated with precultures as described above and evaluated by photometry (OD600) or colony-forming units $\left(\log \mathrm{CFU} \mathrm{mL} \mathrm{m}^{-1}\right)$ after plating serial dilutions on marine agar (cultures with aromatics subcultured twice before plating). In addition, strain 83-1 was tested for degradation of macroalgal tissue (Supplementary Methods). Briefly, healthy specimens of the brown macroalga Ecklonia radiata were incubated with strain 83-1 for 12 days and tissue degradation evaluated in comparison to a control without bacterial addition $(n=15)$.

Screening for bioactive secondary metabolites. Siderophore production was tested with sterile-filtered supernatants of overnight cultures in iron-deplete vs. iron-replete minimal medium using a modified CAS assay ${ }^{143,144}$ with $50 \mu \mathrm{M}$ deferoxamine mesylate (DFOM) and sterile medium as positive and negative controls, respectively. Activity was quantified against a seven-point DFOM standard curve $\left(R^{2}=0.981\right)$. Production of HSLs was tested by streaking Alteromonas colony mass in parallel to the biosensor strains Chromobacterium violaceum CV026 and Agrobacterium tumefaciens A136 according to Ravn and coworkers ${ }^{99}$, with Phaeobacter inhibens DSM17395 as positive control.

Co-culture and quantitative PCR of unique genes. Quantitative PCR (qPCR) was performed using a LightCycler 480 (Roche, Switzerland) according to Berger and coworkers ${ }^{145}$. For a unique gene of each $\mathrm{A}$. macleodii strain, primers were designed using the Roche Universal Probe Library and ordered from TIB MolBiol Germany (Table S5). After confirmation of primer specificity against target and non-target strains, selected strains were grown as mono- and co-cultures in triplicate (inoculated with precultures as described above) in $\mathrm{SWM}+0.1 \%$ glucose at $100 \mathrm{rpm}$ and $20^{\circ} \mathrm{C}$. DNA was extracted using the Master Pure RNA Purification Kit (Epicentre, Madison, WI) and amplified in $15 \mu \mathrm{L}$ qPCR reactions (each $10 \mu \mathrm{L}$ of LightCycler 480 Probes Master, $3 \mu \mathrm{L}$ PCR- $\mathrm{H}_{2} \mathrm{O}, 400 \mathrm{nM}$ of each primer, $200 \mathrm{nM}$ of the respective UPL probe and $5 \mu \mathrm{L}$ template adjusted to $\left.10 \mathrm{ng} \mathrm{LL}^{-1}\right)$. Cycling conditions were $95^{\circ} \mathrm{C}$ for $10 \mathrm{~min}, 45 \mathrm{cycles}\left(95^{\circ} \mathrm{C}\right.$ for $10 \mathrm{~s}, 60^{\circ} \mathrm{C}$ for $30 \mathrm{~s}, 72^{\circ} \mathrm{C}$ for $\left.1 \mathrm{~s}\right)$ and $40^{\circ} \mathrm{C}$ for $30 \mathrm{~s}$. For each biological replicate, three technical PCR replicates were run. Growth was expressed as DNA equivalents in relation to a five-point DNA standard curve for each strain $\left(R^{2}>0.98\right)$.

Biogeography and taxonomic relatives of unique genes. Three genomic loci specific for strains MIT1002, 83-1 and $27126^{\mathrm{T}}$ (Table S6) were searched against TARA Ocean metagenomes using the Sequenceserved-based web application at http://bioinfo.szn.it/tara-blast-server ${ }^{146}$. Detection was considered positive if at least one gene from two loci was detected with $>99 \%$ identity and $>70 \%$ query coverage. Furthermore, unique genes were searched against the NCBI RefSeq Protein database to identify the closest taxonomic relative.

\section{Data availability}

Complete genomes have been deposited at EMBL-EBI under study PRJEB32335 and are also available at IMG ${ }^{147}$ under accession numbers 2738541260, 2738541261, 2738541262, 2738541267 and 2785510739, respectively.

Received: 14 June 2019; Accepted: 23 December 2019;

Published online: 21 January 2020 


\section{References}

1. Larkin, A. A. \& Martiny, A. C. Microdiversity shapes the traits, niche space, and biogeography of microbial taxa. Environ. Microbiol. Rep 9, 55-70, https://doi.org/10.1111/1758-2229.12523 (2017).

2. Farrant, G. K. et al. Delineating ecologically significant taxonomic units from global patterns of marine picocyanobacteria. Proc. Natl. Acad. Sci. USA 113, E3365-E3374, https://doi.org/10.1073/pnas.1524865113 (2016).

3. Riley, M. A. \& Lizotte-Waniewski, M. Population genomics and the bacterial species concept. Methods Mol. Biol 532, 367-377, https://doi.org/10.1007/978-1-60327-853-9_21 (2009).

4. Arevalo, P., VanInsberghe, D. \& Polz, M.F. A Reverse Ecology Framework for Bacteria and Archaea in Population Genomics: Microorganisms (eds. Martin F. Polz \& Om P. Rajora) 77-96 (Springer, 2019).

5. Mira, A., Martín-Cuadrado, A. B., D’Auria, G. \& Rodríguez-Valera, F. The bacterial pan-genome: a new paradigm in microbiology. Int. Microbiol. 13, 45-57, https://doi.org/10.2436/20.1501.01.110 (2010).

6. Freese, H. M. et al. Trajectories and drivers of genome evolution in surface-associated marine Phaeobacter. Genome Biol. Evol 9 , 3297-3311, https://doi.org/10.1093/gbe/evx249 (2017).

7. Kashtan, N. et al. Single-cell genomics reveals hundreds of coexisting subpopulations in wild Prochlorococcus. Science 344, 416-420, https://doi.org/10.1126/science.1248575 (2014).

8. Letzel, A.-C. et al. Genomic insights into specialized metabolism in the marine actinomycete Salinispora. Environ. Microbiol 19, 3660-3673, https://doi.org/10.1111/1462-2920.13867 (2017).

9. López-Pérez, M., Martin-Cuadrado, A.-B. \& Rodriguez-Valera, F. Homologous recombination is involved in the diversity of replacement flexible genomic islands in aquatic prokaryotes. Front. Genet 5, 147, https://doi.org/10.3389/fgene.2014.00147 (2014).

10. Rodriguez-Valera, F., Martin-Cuadrado, A. B. \& López-Pérez, M. Flexible genomic islands as drivers of genome evolution. Curr. Opin. Microbiol. 31, 154-160, https://doi.org/10.1016/j.mib.2016.03.014 (2016).

11. Chan, A. P. et al. A novel method of consensus pan-chromosome assembly and large-scale comparative analysis reveal the highly flexible pan-genome of Acinetobacter baumannii. Genome Biol. 16, 143, https://doi.org/10.1186/s13059-015-0701-6 (2015).

12. Heuer, H. \& Smalla, K. Plasmids foster diversification and adaptation of bacterial populations in soil. FEMS Microbiol. Rev. 36, 1083-1104, https://doi.org/10.1111/j.1574-6976.2012.00337.x (2012).

13. López-Pérez, M., Ramon-Marco, N. \& Rodriguez-Valera, F. Networking in microbes: conjugative elements and plasmids in the genus Alteromonas. BMC Genomics 18, 36, https://doi.org/10.1186/s12864-016-3461-0 (2017).

14. González-Torres, P. \& Gabaldón, T. Genome variation in the model halophilic bacterium Salinibacter ruber. Front. Microbiol 9 , 1499, https://doi.org/10.3389/fmicb.2018.01499 (2018).

15. Sun, Y. \& Luo, H. Homologous recombination in core genomes facilitates marine bacterial adaptation. Appl. Environ. Microbiol. 84, e0254 5-02517, https://doi.org/10.1128/AEM.02545-17 (2018).

16. Sniegowski, P. D. \& Gerrish, P. J. Beneficial mutations and the dynamics of adaptation in asexual populations. Philos. Trans. R. Soc. Lond. B 365, 1255-1263, https://doi.org/10.1098/rstb.2009.0290 (2010).

17. Kirchberger, P. C. et al. A small number of phylogenetically distinct clonal complexes dominate a coastal Vibrio cholerae population. Appl. Environ. Microbiol. 82, 5576-5586, https://doi.org/10.1128/AEM.01177-16 (2016).

18. Hehemann, J.-H. H. et al. Adaptive radiation by waves of gene transfer leads to fine-scale resource partitioning in marine microbes. Nat. Commun. 7, 12860, https://doi.org/10.1038/ncomms12860 (2016).

19. Yawata, Y. et al. Competition-dispersal tradeoff ecologically differentiates recently speciated marine bacterioplankton populations. Proc. Natl. Acad. Sci. USA 111, 5622-5627, https://doi.org/10.1073/pnas.1318943111 (2014).

20. Ziemert, N. et al. Diversity and evolution of secondary metabolism in the marine actinomycete Salinispora. Proc. Natl. Acad. Sci. USA 111, E1130-E1139, https://doi.org/10.1073/pnas.1324161111 (2014).

21. Patin, N. V., Duncan, K. R., Dorrestein, P. C. \& Jensen, P. R. Competitive strategies differentiate closely related species of marine actinobacteria. ISME J. 10, 478-490, https://doi.org/10.1038/ismej.2015.128 (2015).

22. Chase, A. B. et al. Microdiversity of an abundant terrestrial bacterium encompasses extensive variation in ecologically relevant traits. $m$ Bio 8, e01809-01817, https://doi.org/10.1128/mBio.01809-17 (2017).

23. Delmont, T. O. \& Eren, A. M. Linking pangenomes and metagenomes: the Prochlorococcus metapangenome. PeerJ 6, e4320, https:// doi.org/10.7717/peerj.4320 (2018).

24. López-Pérez, M. \& Rodriguez-Valera, F. The family Alteromonadaceae in The Prokaryotes (eds Eugene Rosenberg et al.) 69-92 (Springer, 2014).

25. Wu, S., Zhou, J., Xin, Y. \& Xue, S. Nutritional stress effects under different nitrogen sources on the genes in microalga Isochrysis zhangjiangensis and the assistance of Alteromonas macleodii in releasing the stress of amino acid deficiency. J. Phycol. 51, 885-895, https://doi.org/10.1111/jpy.12328 (2015).

26. Diner, R. E., Schwenck, S. M., McCrow, J. P., Zheng, H. \& Allen, A. E. Genetic manipulation of competition for nitrate between heterotrophic bacteria and diatoms. Front. Microbiol 7, 880, https://doi.org/10.3389/fmicb.2016.00880 (2016).

27. Lee, M. D. et al. The Trichodesmium consortium: conserved heterotrophic co-occurrence and genomic signatures of potential interactions. ISME J. 11, 1813-1824, https://doi.org/10.1038/ismej.2017.49 (2017).

28. Mitulla, M. et al. Response of bacterial communities from California coastal waters to alginate particles and an alginolytic Alteromonas macleodii strain. Environ. Microbiol. 18, 4369-4377, https://doi.org/10.1111/1462-2920.13314 (2016).

29. Taylor, J. D. \& Cunliffe, M. Coastal bacterioplankton community response to diatom-derived polysaccharide microgels. Environ. Microbiol. Rep 9, 151-157, https://doi.org/10.1111/1758-2229.12513 (2017).

30. López-Pérez, M. \& Rodriguez-Valera, F. Pangenome evolution in the marine bacterium Alteromonas. Genome Biol. Evol 8, 1556-1570, https://doi.org/10.1093/gbe/evw098 (2016).

31. Ivars-Martinez, E. et al. Comparative genomics of two ecotypes of the marine planktonic copiotroph Alteromonas macleodii suggests alternative lifestyles associated with different kinds of particulate organic matter. ISME J. 2, 1194-1212, https://doi. org/10.1038/ismej.2008.74 (2008).

32. López-Pérez, M. et al. Genomes of surface isolates of Alteromonas macleodii: the life of a widespread marine opportunistic copiotroph. Sci. Rep 2, 696, https://doi.org/10.1038/srep00696 (2012).

33. Neumann, A. M. et al. Different utilization of alginate and other algal polysaccharides by marine Alteromonas macleodii ecotypes. Environ. Microbiol. 17, 3857-3868, https://doi.org/10.1111/1462-2920.12862 (2015).

34. Gonzaga, A. et al. Polyclonality of concurrent natural populations of Alteromonas macleodii. Genome Biol. Evol 4, 1360-1374, https://doi.org/10.1093/gbe/evs112 (2012).

35. Kimes, N. E., López-Pérez, M., Ausó, E., Ghai, R. \& Rodriguez-Valera, F. RNA sequencing provides evidence for functional variability between naturally co-existing Alteromonas macleodii lineages. BMC Genomics 15, 938, https://doi.org/10.1186/14712164-15-938 (2014).

36. Chafee, M. et al. Recurrent patterns of microdiversity in a temperate coastal marine environment. ISME J. 12, 237-252, https://doi. org/10.1038/ismej.2017.165 (2018).

37. Konstantinidis, K. T. \& Tiedje, J. M. Genomic insights that advance the species definition for prokaryotes. Proc. Natl. Acad. Sci. USA 102, 2567-2572, https://doi.org/10.1073/pnas.0409727102 (2005).

38. López-Pérez, M., Gonzaga, A. \& Rodriguez-Valera, F. Genomic diversity of “deep ecotype” Alteromonas macleodii isolates: evidence for Pan-Mediterranean clonal frames. Genome Biol. Evol 5, 1220-1232, https://doi.org/10.1093/gbe/evt089 (2013). 
39. López-Pérez, M. et al. Intra- and intergenomic variation of ribosomal RNA operons in concurrent Alteromonas macleodii strains. Microb. Ecol. 65, 720-730, https://doi.org/10.1007/s00248-012-0153-4 (2013).

40. MacLean, R. C. \& San Millan, A. Microbial evolution: towards resolving the plasmid paradox. Curr. Biol. 25, R764-R767, https:// doi.org/10.1016/J.CUB.2015.07.006 (2015).

41. Hou, S. et al. Benefit from decline: the primary transcriptome of Alteromonas macleodii str. Te101 during Trichodesmium demise. ISME J. 12, 981-996, https://doi.org/10.1038/s41396-017-0034-4 (2018).

42. Vargas, W. A., Weyman, P. D., Tong, Y., Smith, H. O. \& Xu, Q. [NiFe] hydrogenase from Alteromonas macleodii with unusual stability in the presence of oxygen and high temperature. Appl. Environ. Microbiol. 77, 1990-1998, https://doi.org/10.1128/ AEM.01559-10 (2011)

43. Fadeev, E. et al. Why close a bacterial genome? The plasmid of Alteromonas macleodii HOT1A3 is a vector for inter-specific transfer of a flexible genomic Island. Front. Microbiol 7, 248, https://doi.org/10.3389/fmicb.2016.00248 (2016)

44. López-Pérez, M., Gonzaga, A., Ivanova, E. P. \& Rodriguez-Valera, F. Genomes of Alteromonas australica, a world apart. BMC Genomics 15, 483, https://doi.org/10.1186/1471-2164-15-483 (2014).

45. Bryant, J. A., Sellars, L. E., Busby, S. J. W. \& Lee, D. J. Chromosome position effects on gene expression in Escherichia coli K-12. Nucleic Acids Res 42, 11383-11392, https://doi.org/10.1093/nar/gku828 (2014).

46. Stocker, R. \& Seymour, J. R. Ecology and physics of bacterial chemotaxis in the ocean. Microbiol. Mol. Biol. Rev. 76, 792-812, https://doi.org/10.1128/MMBR.00029-12 (2012).

47. Iwaki, H., Yamamoto, T. \& Hasegawa, Y. Isolation of marine xylene-utilizing bacteria and characterization of Halioxenophilus aromaticivorans gen. nov., sp. nov. and its xylene degradation gene cluster. FEMS Microbiol. Lett. 365, https://doi.org/10.1093/ femsle/fny042 (2018).

48. Berlendis, S. et al. First evidence of aerobic biodegradation of BTEX compounds by pure cultures of Marinobacter. Appl. Biochem. Biotechnol. 160, 1992-1999, https://doi.org/10.1007/s12010-009-8746-1 (2010).

49. Burlage, R. S., Hooper, S. W. \& Sayler, G. S. The TOL (pWW0) catabolic plasmid. Appl. Environ. Microbiol 55, 1323-1328 (1989).

50. Medema, M. H., Takano, E. \& Breitling, R. Detecting sequence homology at the gene cluster level with MultiGeneBlast. Mol. Biol. Evol 30, 1218-1223, https://doi.org/10.1093/molbev/mst025 (2013).

51. Gutierrez, T. Marine, Aerobic Hydrocarbon-Degrading Gammaproteobacteria: Overview in Taxonomy, Genomics and Ecophysiology of Hydrocarbon-Degrading Microbes (ed. McGenity, T.) 1-10 (Springer, 2017).

52. Handley, K. \& Lloyd, J. Biogeochemical implications of the ubiquitous colonization of marine habitats and redox gradients by Marinobacter species. Front. Microbiol 4, 136, https://doi.org/10.3389/fmicb.2013.00136 (2013).

53. Hedlund, B. P. \& Staley, J. T. Isolation and characterization of Pseudoalteromonas strains with divergent polycyclic aromatic hydrocarbon catabolic properties. Environ. Microbiol. 8, 178-182, https://doi.org/10.1111/j.1462-2920.2005.00871.x (2006).

54. Green, D. H., Bowman, J. P., Smith, E. A., Gutierrez, T. \& Bolch, C. J. S. Marinobacter algicola sp. nov., isolated from laboratory cultures of paralytic shellfish toxin-producing dinoflagellates. Int. J. Syst. Evol. Microbiol. 56, 523-527, https://doi.org/10.1099/ ijs.0.63447-0 (2006)

55. Gärdes, A., Iversen, M. H., Grossart, H.-P., Passow, U. \& Ullrich, M. S. Diatom-associated bacteria are required for aggregation of Thalassiosira weissflogii. ISME J. 5, 436-445, https://doi.org/10.1038/ismej.2010.145 (2011).

56. Zyszka-Haberecht, B., Niemczyk, E. \& Lipok, J. Metabolic relation of cyanobacteria to aromatic compounds. Appl. Microbiol. Biotechnol. 103, 1167-1178, https://doi.org/10.1007/s00253-018-9568-2 (2019).

57. Kastman, E. K. et al. Biotic interactions shape the ecological distributions of Staphylococcus species. mBio 7, e01157-01116, https:// doi.org/10.1128/mBio.01157-16 (2016)

58. Morris, J. J., Johnson, Z. I., Szul, M. J., Keller, M. \& Zinser, E. R. Dependence of the cyanobacterium Prochlorococcus on hydrogen peroxide scavenging microbes for growth at the ocean's surface. PLoS One 6, el6805, https://doi.org/10.1371/journal.pone.0016805 (2011).

59. Biller, S. J., Coe, A., Roggensack, S. E. \& Chisholm, S. W. Heterotroph interactions alter Prochlorococcus transcriptome dynamics during extended periods of darkness. mSystems 3, e00040-18, https://doi.org/10.1128/mSystems.00040-18 (2018).

60. Morris, J. J., Kirkegaard, R., Szul, M. J., Johnson, Z. I. \& Zinser, E. R. Facilitation of robust growth of Prochlorococcus colonies and dilute liquid cultures by "helper" heterotrophic bacteria. Appl. Environ. Microbiol. 74, 4530-4534, https://doi.org/10.1128/ AEM.02479-07 (2008).

61. Biller, S. J., Coe, A., Martin-Cuadrado, A.-B. \& Chisholm, S. W. Draft genome sequence of Alteromonas macleodii strain MIT1002, isolated from an enrichment culture of the marine cyanobacterium Prochlorococcus. Genome Announc. 3, e00967-00915, https:// doi.org/10.1128/genomeA.00967-15 (2015).

62. Biller, S. J., Coe, A. \& Chisholm, S. W. Torn apart and reunited: impact of a heterotroph on the transcriptome of Prochlorococcus. ISME J. 10, 2831-2843, https://doi.org/10.1038/ismej.2016.82 (2016).

63. Fiore, C. L., Longnecker, K., Kido Soule, M. C. \& Kujawinski, E. B. Release of ecologically relevant metabolites by the cyanobacterium Synechococcus elongatus CCMP 1631. Environ. Microbiol. 17, 3949-3963, https://doi.org/10.1111/14622920.12899 (2015).

64. Aharonovich, D. \& Sher, D. Transcriptional response of Prochlorococcus to co-culture with a marine Alteromonas: differences between strains and the involvement of putative infochemicals. ISME J. 10, 2892-2906, https://doi.org/10.1038/ismej.2016.70 (2016).

65. Hennon, G. M. M. et al. The impact of elevated CO on Prochlorococcus and microbial interactions with 'helper' bacterium Alteromonas. ISME J. 12, 520-531, https://doi.org/10.1038/ismej.2017.189 (2018).

66. Yelton, A. P. et al. Global genetic capacity for mixotrophy in marine picocyanobacteria. ISME J. 10, 2946-2957, https://doi. org/10.1038/ismej.2016.64 (2016).

67. Zubkov, M. V. \& Tarran, G. A. Amino acid uptake of Prochlorococcus spp. in surface waters across the South Atlantic Subtropical Front. Aquat. Microb. Ecol. 40, 241-249, https://doi.org/10.3354/ame040241 (2005).

68. Seth, E. C. \& Taga, M. E. Nutrient cross-feeding in the microbial world. Front. Microbiol 5, 350, https://doi.org/10.3389/ fmicb.2014.00350 (2014)

69. Pacheco, A. R., Moel, M. \& Segrè, D. Costless metabolic secretions as drivers of interspecies interactions in microbial ecosystems. Nat. Commun. 10, 103, https://doi.org/10.1038/s41467-018-07946-9 (2019).

70. Seymour, J. R., Ahmed, T., Durham, W. M. \& Stocker, R. Chemotactic response of marine bacteria to the extracellular products of Synechococcus and Prochlorococcus. Aquat. Microb. Ecol. 59, 161-168, https://doi.org/10.3354/ame01400 (2010).

71. Richardson, B. \& Corcoran, A. A. Use of dissolved inorganic and organic phosphorus by axenic and nonaxenic clones of Karenia brevis and Karenia mikimotoi. Harmful Algae 48, 30-36, https://doi.org/10.1016/J.HAL.2015.06.005 (2015).

72. Scanlan, D. J. et al. Ecological genomics of marine picocyanobacteria. Microbiol. Mol. Biol. Rev. 73, 249-299, https://doi. org/10.1128/MMBR.00035-08 (2009).

73. Partensky, F. \& Garczarek, L. Prochlorococcus: advantages and limits of minimalism. Annu. Rev. Mar. Sci 2, 305-331, https://doi. org/10.1146/annurevmarine-120308-081034 (2009).

74. Koch, H. et al. Biphasic cellular adaptations and ecological implications of Alteromonas macleodii degrading a mixture of algal polysaccharides. ISME J. 13, 92-103, https://doi.org/10.1038/s41396-018-0252-4 (2019).

75. Levy, A. et al. Genomic features of bacterial adaptation to plants. Nat. Genet. 50, 138-150, https://doi.org/10.1038/s41588-0170012-9 (2018) 
76. Qiu, Z. et al. Future climate change is predicted to affect the microbiome and condition of habitat-forming kelp. Proc. R. Soc. B 286, https://doi.org/10.1098/rspb.2018.1887 (2019).

77. Marzinelli, E. M. et al. Continental-scale variation in seaweed host-associated bacterial communities is a function of host condition, not geography. Environ. Microbiol. 17, 4078-4088, https://doi.org/10.1111/1462-2920.12972 (2015).

78. Zhu, Y. et al. Genetic analyses unravel the crucial role of a horizontally acquired alginate lyase for brown algal biomass degradation by Zobellia galactanivorans. Environ. Microbiol. 19, 2164-2181, https://doi.org/10.1111/1462-2920.13699 (2017).

79. Lin, J. D., Lemay, M. A. \& Parfrey, L. W. Diverse bacteria utilize alginate within the microbiome of the giant kelp Macrocystis pyrifera. Front. Microbiol 9, 1914, https://doi.org/10.3389/fmicb.2018.01914 (2018).

80. Saha, M. \& Weinberger, F. Microbial "gardening" by a seaweed holobiont: surface metabolites attract protective and deter pathogenic epibacterial settlement. J. Ecol. 107, 2255-2265, https://doi.org/10.1111/1365-2745.13193 (2019).

81. Duchêne, S. et al. Genome-scale rates of evolutionary change in bacteria. Microb. Genomics 2, e000094, https://doi.org/10.1099/ mgen.0.000094 (2016).

82. Freese, H. M., Methner, A. \& Overmann, J. Adaptation of surface-associated bacteria to the open ocean: a genomically distinct subpopulation of Phaeobacter gallaeciensis colonizes Pacific mesozooplankton. Front. Microbiol 8, 1659, https://doi.org/10.3389/ fmicb.2017.01659 (2017).

83. Postle, K. \& Kadner, R. J. Touch and go: tying TonB to transport. Mol. Microbiol 49, 869-882, https://doi.org/10.1046/j.13652958.2003.03629.x (2003).

84. Fitzpatrick, T. B. et al. Two independent routes of de novo vitamin B biosynthesis: not that different after all. Biochem. J 407, 1-13, https://doi.org/10.1042/BJ20070765 (2007).

85. Tazzyman, S. J. \& Bonhoeffer, S. Why there are no essential genes on plasmids. Mol. Biol. Evol. 32, 3079-3088, https://doi. org/10.1093/molbev/msu293 (2014).

86. Lau, B. T. C., Malkus, P. \& Paulsson, J. New quantitative methods for measuring plasmid loss rates reveal unexpected stability. Plasmid 70, 353-361, https://doi.org/10.1016/j.plasmid.2013.07.007 (2013).

87. Grondin, J. M., Tamura, K., Déjean, G., Abbott, D. W. \& Brumer, H. Polysaccharide Utilization Loci: fuelling microbial communities. J. Bacteriol. 199, JB.00860-16, https://doi.org/10.1128/JB.00860-16 (2017).

88. Tang, K., Lin, Y., Han, Y. \& Jiao, N. Characterization of potential Polysaccharide Utilization Systems in the marine Bacteroidetes Gramella flava JLT2011 using a multi-omics approach. Front. Microbiol 8, 220, https://doi.org/10.3389/fmicb.2017.00220 (2017).

89. Foran, E. et al. Functional characterization of a novel "ulvan utilization loci" found in Alteromonas sp. LOR genome. Algal Res 25 , 39-46, https://doi.org/10.1016/j.algal.2017.04.036 (2017).

90. Koch, H., Freese, H. M., Hahnke, R., Simon, M. \& Wietz, M. Adaptations of Alteromonas sp. 76-1 to polysaccharide degradation: a CAZyme plasmid for ulvan degradation and two alginolytic systems. Front. Microbiol 10, 504, https://doi.org/10.3389/ fmicb.2019.00504 (2019).

91. Kappelmann, L. et al. Polysaccharide utilization loci of North Sea Flavobacteriia as basis for using SusC/D-protein expression for predicting major phytoplankton glycans. ISME J. 13, 76-91, https://doi.org/10.1038/s41396-018-0242-6 (2019).

92. Pujalte, M. J., Sitjà-Bobadilla, A., Álvarez-Pellitero, P. \& Garay, E. Carriage of potentially fish-pathogenic bacteria in Sparus aurata cultured in Mediterranean fish farms. Dis. Aquat. Org 54, 119-126, https://doi.org/10.3354/dao054119 (2003).

93. Helbert, W. Marine polysaccharide sulfatases. Front. Mar. Sci 4, 6, https://doi.org/10.3389/fmars.2017.00006 (2017).

94. Torrecillas, S., Montero, D. \& Izquierdo, M. Improved health and growth of fish fed mannan oligosaccharides: potential mode of action. Fish. Shellfish. Immunol. 36, 525-544, https://doi.org/10.1016/j.fsi.2013.12.029 (2014).

95. Sheridan, P. O. et al. Polysaccharide utilization loci and nutritional specialization in a dominant group of butyrate-producing human colonic Firmicutes. Microb. Genomics 2, e000043, https://doi.org/10.1099/mgen.0.000043 (2016).

96. Hmelo, L. R. Quorum Sensing in marine microbial environments. Annu. Rev. Mar. Sci 9, 257-281, https://doi.org/10.1146/ annurev-marine-010816-060656 (2017).

97. Blin, K. et al. antiSMASH 4.0-improvements in chemistry prediction and gene cluster boundary identification. Nucleic Acids Res. 45, W36-W41, https://doi.org/10.1093/nar/gkx319 (2017).

98. Doberva, M. et al. Large diversity and original structures of acyl-homoserine lactones in strain MOLA 401, a marine Rhodobacteraceae bacterium. Front. Microbiol 8, 1152, https://doi.org/10.3389/fmicb.2017.01152 (2017).

99. Ravn, L., Christensen, A. B., Molin, S., Givskov, M. \& Gram, L. Methods for detecting acylated homoserine lactones produced by Gram-negative bacteria and their application in studies of AHL-production kinetics. J. Microbiol. Methods 44, 239-251, https://doi. org/10.1016/S0167-7012(01)00217-2 (2001).

100. Doberva, M., Sanchez-Ferandin, S., Toulza, E., Lebaron, P. \& Lami, R. Diversity of quorum sensing autoinducer synthases in the Global Ocean Sampling metagenomic database. Aquat. Microb. Ecol. 74, 107-119, https://doi.org/10.3354/ame01734 (2015).

101. Girard, L. et al. Evidence of a large diversity of $N$-acyl-homoserine lactones in symbiotic Vibrio fischeri strains associated with the squid Euprymna scolopes. Microbes Environ. 34, 99-103, https://doi.org/10.1264/jsme2.ME18145 (2019).

102. Tagliabue, A. et al. The integral role of iron in ocean biogeochemistry. Nature 543, 51-59, https://doi.org/10.1038/nature21058 (2017).

103. Sandy, M. \& Butler, A. Microbial iron acquisition: marine and terrestrial siderophores. Chem. Rev. 109, 4580-4595, https://doi. org/10.1021/cr9002787 (2009)

104. Boiteau, R. M. et al. Siderophore-based microbial adaptations to iron scarcity across the eastern Pacific Ocean. Proc. Natl. Acad. Sci. USA 113, 14237-14242, https://doi.org/10.1073/pnas.1608594113 (2016)

105. Dinkla, I. J., Gabor, E. M. \& Janssen, D. B. Effects of iron limitation on the degradation of toluene by Pseudomonas strains carrying the TOL (pWWO) plasmid. Appl. Environ. Microbiol. 67, 3406-3412, https://doi.org/10.1128/AEM.67.8.3406-3412.2001 (2001).

106. Tappin, A. D. \& Millward, G. E. The English Channel: contamination status of its transitional and coastal waters. Mar. Pollut. Bull. 95, 529-550, https://doi.org/10.1016/J.MARPOLBUL.2014.12.012 (2015)

107. Vital, M. et al. Gene expression analysis of $E$. coli strains provides insights into the role of gene regulation in diversification. ISME J. 9, 1130-1140, https://doi.org/10.1038/ismej.2014.204 (2015).

108. Waite, A. J. et al. Non-genetic diversity modulates population performance. Mol. Syst. Biol. 12, 895, https://doi.org/10.15252/ msb.20167044 (2016)

109. Hibbing, M. E., Fuqua, C., Parsek, M. R. \& Peterson, S. B. B. Bacterial competition: surviving and thriving in the microbial jungle. Nat. Rev. Microbiol. 8, 15-25, https://doi.org/10.1038/nrmicro2259 (2010).

110. Hansell, D. A. \& Carlson, C. A. Biogeochemistry of marine dissolved organic matter (Academic Press, 2014).

111. Dang, H. \& Lovell, C. R. Microbial surface colonization and biofilm development in marine environments. Microbiol. Mol. Biol. Rev. 80, 91-138, https://doi.org/10.1128/MMBR.00037-15 (2016).

112. Partensky, F., Hess, W. R. \& Vaulot, D. Prochlorococcus, a marine photosynthetic prokaryote of global significance. Microbiol. Mol. Biol. Rev 63, 106-127 (1999).

113. Fuchsman, C. A., Collins, R. E., Rocap, G. \& Brazelton, W. J. Effect of the environment on horizontal gene transfer between bacteria and archaea. PeerJ 5, e3865, https://doi.org/10.7717/peerj.3865 (2017).

114. Hoetzinger, M., Schmidt, J., Jezberova, J., Koll, U. \& Hahn, M. W. Microdiversification of a pelagic Polynucleobacter species is mainly driven by acquisition of genomic islands from a partially interspecific gene pool. Appl. Environ. Microbiol. 83, e02266-16, https://doi.org/10.1128/aem.02266-16 (2017). 
115. Shapiro, B. J. \& Polz, M. F. Ordering microbial diversity into ecologically and genetically cohesive units. Trends Microbiol. 22, 235-247, https://doi.org/10.1016/j.tim.2014.02.006 (2014).

116. Cohan, F. M. Transmission in the origins of bacterial diversity, from ecotypes to phyla. Microbiol. Spectr. 5, https://doi.org/10.1128/ microbiolspec.MTBP-0014-2016 (2017).

117. Simon, M. Functional diversity of bacterial communities and the geometabolome in the central and north Pacific (BacGeoPac). Cruise Report SO248, German Research Fleet Coordination Centre, University of Hamburg (2016).

118. Eren, A. M. et al. Anvio: an advanced analysis and visualization platform for 'omics data. PeerJ 3, e1319, https://doi.org/10.7717/ peerj.1319 (2015)

119. Na, S.-I. et al. UBCG: Up-to-date bacterial core gene set and pipeline for phylogenomic tree reconstruction. J. Microbiol. 56, 281-285, https://doi.org/10.1007/s12275-018-8014-6 (2018).

120. Trifinopoulos, J., Nguyen, L.-T., Minh, B. Q. \& von Haeseler, A. W-IQ-TREE: a fast online phylogenetic tool for maximum likelihood analysis. Nucleic Acids Res. 44, W232-W235, https://doi.org/10.1093/nar/gkw256 (2016).

121. Darriba, D., Taboada, G. L., Doallo, R. \& Posada, D. jModelTest 2: more models, new heuristics and parallel computing. Nat. Methods 9, 772, https://doi.org/10.1038/nmeth.2109 (2012).

122. Rodriguez-R, L. M. \& Konstantinidis, K. T. The enveomics collection: a toolbox for specialized analyses of microbial genomes and metagenomes. PeerJ Preprints 4, e1900v1, https://doi.org/10.7287/PEERJ.PREPRINTS.1900V1 (2016).

123. Treangen, T. J., Ondov, B. D., Koren, S. \& Phillippy, A. M. The Harvest suite for rapid core-genome alignment and visualization of thousands of intraspecific microbial genomes. Genome Biol. 15, 524, https://doi.org/10.1186/s13059-014-0524-x (2014).

124. Hall, T. A. BioEdit: a user-friendly biological sequence alignment editor and analysis program for Windows 95/98/NT. Nucleic Acids Symposium Ser. 41, 95-98 (1999).

125. Arndt, D. et al. PHASTER: a better, faster version of the PHAST phage search tool. Nucleic Acids Res. 44, W16-21, https://doi. org/10.1093/nar/gkw387 (2016).

126. Zhang, H. et al. dbCAN2: a meta server for automated carbohydrate-active enzyme annotation. Nucleic Acids Res. 46, W95-W101, https://doi.org/10.1093/nar/gky418 (2018).

127. Kolde, R. Package 'pheatmap', https://cran.r-project.org/web/packages/pheatmap/index.html (2018).

128. Moriya, Y., Itoh, M., Okuda, S., Yoshizawa, A. C. \& Kanehisa, M. KAAS: an automatic genome annotation and pathway reconstruction server. Nucleic Acids Res. 35, W182-W185, https://doi.org/10.1093/nar/gkm321 (2007).

129. Kanehisa, M., Sato, Y. \& Morishima, K. BlastKOALA and GhostKOALA: KEGG tools for functional characterization of genome and metagenome sequences. J. Mol. Biol. 428, 726-731, https://doi.org/10.1016/j.jmb.2015.11.006 (2016).

130. Boutet, E. et al. UniProtKB/Swiss-Prot, the manually annotated section of the UniProt KnowledgeBase: How to use the Entry View. Methods Mol Biol 1374, 23-54, https://doi.org/10.1007/978-1-4939-3167-5_2 (2016).

131. Potter, S. C. et al. HMMER web server: 2018 update. Nucleic Acids Res. 46, W200-W204, https://doi.org/10.1093/nar/gky448 (2018).

132. Katoh, K., Misawa, K., Kuma, K.-I. \& Miyata, T. MAFFT: a novel method for rapid multiple sequence alignment based on fast Fourier transform. Nucleic Acids Res 30, 3059-3066, https://doi.org/10.1093/nar/gkf436 (2002).

133. Tamura, K., Stecher, G., Peterson, D., Filipski, A. \& Kumar, S. MEGA6: Molecular Evolutionary Genetics Analysis version 6.0. Mol. Biol. Evol 30, 2725-2729, https://doi.org/10.1093/molbev/mst197 (2013).

134. Darriba, D., Taboada, G. L., Doallo, R. \& Posada, D. ProtTest 3: fast selection of best-fit models of protein evolution. Bioinformatics 27, 1164-1165, https://doi.org/10.1093/bioinformatics/btr088 (2011)

135. R: A language and environment for statistical computing. R Foundation for Statistical Computing, Vienna, Austria (2018).

136. Zech, H. et al. Growth phase-dependent global protein and metabolite profiles of Phaeobacter gallaeciensis strain DSM 17395, a member of the marine Roseobacter-clade. Proteomics 9, 3677-3697, https://doi.org/10.1002/pmic.200900120 (2009).

137. Dittmar, T., Koch, B., Hertkorn, N. \& Kattner, G. A simple and efficient method for the solid-phase extraction of dissolved organic matter (SPE-DOM) from seawater. Limnol. Oceanogr. Methods 6, 230-235, https://doi.org/10.4319/lom.2008.6.230 (2008)

138. Seidel, M. et al. Biogeochemistry of dissolved organic matter in an anoxic intertidal creek bank. Geochim. Cosmochim. Acta 140, 418-434, https://doi.org/10.1016/j.gca.2014.05.038 (2014).

139. Osterholz, H. et al. Deciphering associations between dissolved organic molecules and bacterial communities in a pelagic marine system. ISME J. 10, 1717-1730, https://doi.org/10.1038/ismej.2015.231 (2016).

140. Caspi, R. et al. The MetaCyc database of metabolic pathways and enzymes and the BioCyc collection of Pathway/Genome Databases. Nucleic Acids Res. 42, D459-471, https://doi.org/10.1093/nar/gkt1103 (2014).

141. Kanehisa, M., Furumichi, M., Tanabe, M., Sato, Y. \& Morishima, K. KEGG: new perspectives on genomes, pathways, diseases and drugs. Nucleic Acids Res. 45, D353-D361, https://doi.org/10.1093/nar/gkw1092 (2017).

142. Tenenbaum, D. KEGGREST: client-side REST access to KEGG, http://bioconductor.org/packages/release/bioc/html/KEGGREST. html (2018).

143. Schwyn, B. \& Neilands, J. B. Universal chemical assay for the detection and determination of siderophores. Anal. Biochem. 160, 47-56, https://doi.org/10.1016/0003-2697(87)90612-9(1987).

144. Alexander, D. B. \& Zuberer, D. A. Use of chrome azurol S reagents to evaluate siderophore production by rhizosphere bacteria. Biol. Fertil. Soils 12, 39-45, https://doi.org/10.1007/BF00369386 (1991).

145. Berger, M., Neumann, A., Schulz, S., Simon, M. \& Brinkhoff, T. Tropodithietic acid production in Phaeobacter gallaeciensis is regulated by $N$-acyl homoserine lactone-mediated quorum sensing. J. Bacteriol. 193, 6576-6585, https://doi.org/10.1128/JB.05818-11 (2011).

146. Priyam, A. et al. Sequenceserver: a modern graphical user interface for custom BLAST databases. Mol. Biol. Evol 36, 2922-2924, https://doi.org/10.1093/molbev/msz185 (2019).

147. Chen, I. M. A. et al. IMG/M: integrated genome and metagenome comparative data analysis system. Nucleic Acids Res. 45, D507-D516, https://doi.org/10.1093/nar/gkw929 (2017).

\section{Acknowledgements}

We thank Steven Biller, Allison Coe, Erik Zinser, Spiro Papoulis, Daniel Sher and Dikla Aharonovich for kindly sharing strains MIT1002, EZ55 and HOT1A3. Excellent technical assistance was provided by Katrin Klaproth, Matthias Friebe (FT-ICR-MS) and Cathrin Spröer (genome sequencing). We are grateful to captain, crew and scientists of RV Sonne expedition SO248; supported by grant BacGeoPac 03G0248A (German Ministry of Education and Research; BMBF). Francisco Rodriguez-Valera, Mario López-Pérez, Jutta Niggemann, JanHendrik Hehemann and Kai Bischof are thanked for helpful suggestions. M.W. and H.F. were supported by German Research Foundation (DFG) through grants WI3888/1-2 and TRR 51/2-3 TA07, respectively. H.K. was supported by Volkswagen Foundation under VW-Vorab grant 'Marine Biodiversity across Scales' (MarBAS; ZN3112) and the Radboud Excellence Initiative. E.M. and P.S. received funding from the Australian Research Council (DP180104041). 


\section{Author contributions}

M.W. and H.K. designed the study. H.F. and J.O. carried out whole-genome sequencing, assembly and annotation. H.K., M.W., N.G. and M.B. carried out genome analyses and physiological experiments. B.N.O. and T.D. performed exometabolomic analyses. N.G., D.L. and M.B. designed and performed qPCR. G.Q., E.M., A.C. and P.S. designed and performed incubation experiments with live algae. H.K., M.W., H.F. and M.S. wrote the manuscript, with contributions from all authors.

\section{Competing interests}

The authors declare no competing interests.

\section{Additional information}

Supplementary information is available for this paper at https://doi.org/10.1038/s41598-020-57526-5.

Correspondence and requests for materials should be addressed to M.W.

Reprints and permissions information is available at www.nature.com/reprints.

Publisher's note Springer Nature remains neutral with regard to jurisdictional claims in published maps and institutional affiliations.

(c) (i) Open Access This article is licensed under a Creative Commons Attribution 4.0 International License, which permits use, sharing, adaptation, distribution and reproduction in any medium or format, as long as you give appropriate credit to the original author(s) and the source, provide a link to the Creative Commons license, and indicate if changes were made. The images or other third party material in this article are included in the article's Creative Commons license, unless indicated otherwise in a credit line to the material. If material is not included in the article's Creative Commons license and your intended use is not permitted by statutory regulation or exceeds the permitted use, you will need to obtain permission directly from the copyright holder. To view a copy of this license, visit http://creativecommons.org/licenses/by/4.0/.

(c) The Author(s) 2020 